\title{
Percepções dos filhos sobre aspectos reais e ideais do cuidado parental
}

\author{
Children's perceptions of the real and ideal \\ aspects of parental care
}

\author{
Everley Rosane GOETZ \\ Mauro Luís VIEIRA ${ }^{2}$
}

\begin{abstract}
Resumo
Esta pesquisa teve como objetivo principal identificar a percepção que as crianças têm em relação ao comportamento paterno de cuidado e as diferenças em relação ao materno. Participaram do estudo 216 crianças de duas escolas da rede municipal de ensino de Florianópolis, com faixa etária compreendida entre 10 e 11 anos. Os instrumentos utilizados foram dois questionários, contendo perguntas fechadas e abertas. Para analisar as questões, utilizou-se análise estatística e temática de conteúdo. Os resultados indicam diferenças significativas entre a percepção que os filhos têm do pai real em relação ao ideal. Quanto à percepção real da mãe, aproxima-se do ideal dos filhos. Como conclusão geral, pode-se afirmar que as crianças percebem o pai real bastante afastado do ideal em aspectos referentes ao cuidado e à interação. Quanto à mãe real, ela está predominantemente mais próxima do modelo ideal percebido nesses mesmos aspectos.
\end{abstract}

Unitermos: Cuidado parental. Filhos. Percepção. Sistêmica.

\begin{abstract}
The main objective of the present study is to identify if the perception that children have of paternal behavior differs from their perception of maternal behavior. A total of 216 children aged 10-11, in regular attendance at municipal schools in Florianopolis, participated in the study. Two questionnaires were used containing both closed and scale-type questions. To analyze the closed questions, the Ttest was used for each pair of answers. The results of the scale of paternity signify that there is a significant difference between the perceptions that children have of theirfather (real vs. ideal). As for the perception of the mother, there was aless significant difference. As a general conclusion, it may be said that children perceive the real father as quite removed from the ideal one in aspects relating to care and interaction. As far as the real mother is concerned, she is predominantly closer to the ideal model for these same aspects.
\end{abstract}

Uniterms: Parental care. Children. Perception. Systemic.

A importância da qualidade da relação da mãe com a criança é reconhecida como fundamental para os aspectos mais relevantes do desenvolvimento humano (Bandeira, Goetz, Vieira \& Pontes, 2005). Segundo Lewis e Dessen (1999), há certo desequilíbrio em pesquisa, uma vez que geralmente se assume que a

\footnotetext{
$\boldsymbol{\nabla \nabla \nabla \boldsymbol { \nabla }}$

1 Universidade Federal de Santa Catarina, Programa de Pós-Graduação em Psicologia. Florianópolis, SC, Brasil.

2 Universidade Federal de Santa Catarina, Departamento de Psicologia. Campus Universitário, Trindade, 88040-900, Florianópolis, SC, Brasil. Correspondência para/Correspondence to: M.L. VIEIRA. E-mail:<mvieira@cfh.ufsc.br>.

Agradecimento: aos alunos participantes, aos professores e equipes pedagógicas de duas escolas municipais da cidade de Florianópolis pela intensa colaboração nesta pesquisa que é derivada da dissertação "Percepções dos filhos sobre aspectos reais e ideais do cuidado parental". Universidade Federal de Santa Catarina, 2005.
} 
mãe é figura-chave para os pesquisadores e também a informante-chave para eles. Mas, reconhecida a complexidade das relações familiares, deve-se tentar compreender igualmente o papel do pai, visto que ele integra tanto a ecologia da família como processos sociais mais amplos.

Embora nas últimas três décadas tenha ocorrido um crescente interesse da psicologia pela interação do pai com a criança (Bandeira et al., 2005; Fleck \&Wagner, 2003; Geary \& Flinn, 2001; Klaus, Kennell \& Klaus, 2000; Lewis, 2000; Prado, 2005; Veneziano, 2003; Wagner, Predebon, Mosmann \& Verza, 2005), para a compreensão da função deste no desenvolvimento humano os resultados das pesquisas são ainda inconclusivos (Maridaki-Kassotaki, 2001), indicando a necessidade de ampliar pesquisas na área.

É provável que o interesse pelo papel do pai no desenvolvimento infantil esteja associado às mudanças ocorridas nas configurações familiares vigentes (Araújo, 2002; Aspesi, Dessen \& Chagas, 2005; Bandeira et al., 2005; Wagner et al., 2005), nas quais as atribuições e responsabilidades de cada progenitor não são mais rigidamente estabelecidas, tendo em vista o aumento de mulheres que trabalham fora de casa e também o grande número de famílias constituídas por apenas um membro parental.

Considerando as mudanças na constituição familiar ocorrida nos últimos anos e as possíveis alterações que o papel do pai pode ter sofrido em decorrência destas alterações (Araújo, 2002; Bandeira et al., 2005; Fleck \&Wagner, 2003; Prado, 2005; Wagner et al., 2005), buscou-se identificar como é desempenhado o papel paterno no sistema familiar. A família é vista, aqui, como um microssistema que integra e está contido em sistemas maiores que a influenciam - família, escola, ocupação dos pais, dentre outros (Bronfenbrenner, 2002). Para este autor, a família de hoje deve ser concebida, do ponto de vista do desenvolvimento, sob uma perspectiva sistêmica. Adotou-se, neste estudo, a perspectiva ecossistêmica, especificamente relacionada ao desenvolvimento, que considera a interdependência de múltiplos sistemas com o ambiente em que se situam, ao longo do tempo (Bronfenbrenner, 1986, 1994, 2002; Bronfenbrenner \& Evans, 2000; Polonia, Dessen \& Silva, 2005).

O objetivo deste estudo foi a compreensão das

196 percepções das crianças a respeito do papel paterno real, em comparação com suas expectativas em relação ao papel paterno ideal, além de investigar se as percepções reais e ideais entre comportamento paterno e materno de cuidado diferem entre si, considerando possíveis implicações para o desenvolvimento infantil. As percepções das crianças sobre comportamentos parentais de cuidado são compreendidas a partir de suas atividades, papéis e relações humanas (subjetivas e objetivas) estabelecidas com os próprios pais.

Com base nesses princípios, as percepções dos sujeitos deste estudo sobre cuidado parental foram abordadas tanto ao nível real quanto ideal. Entende-se por real o que é verdadeiro ou relativo às preocupações e atividades diárias e rotineiras. A realidade pode ser definida como uma qualidade pertencente a fenômenos com uma existência em si - ou seja, não se pode desejar que não existam. Por ideal, aceita-se aquilo que é relativo à ideia, que só existe no pensamento e que possui, em grau superlativo, as qualidades positivas de sua espécie, ou que se ajusta exatamente a um modelo simbólico; refere-se a realidades diferentes das pertencentes à experiência da vida cotidiana, contendo todos os significados socialmente objetivados e subjetivamente reais (Berger \& Luckmann, 2000).

Dessen e Braz (2000) estudaram o comportamento paterno ideal na percepção das mães e dos pais e sugeriram que, para a mãe, o pai é apontado como a principal fonte de apoio, quando está presente no meio familiar. O pai considera que o suporte econômico que ele provê constitui o apoio de maior relevância para o bem-estar dos filhos. Esses dados sugerem que pais e mães têm valores diferentes, possivelmente associados aos papéis de gênero feminino e masculino. Em concordância com estudos anteriores (Coelho, 2000; Lewis, 2000), Dessen e Braz (2000) e Wagner et al. (2005) concluíram que, embora haja uma forte tendência a mudanças nos valores referentes aos papéis atribuídos ao pai nos tempos atuais, os relatos dos pais e das mães sugerem que as mulheres continuam valorizando um papel de guardiãs da situação emocional e afetiva, enquanto os homens atribuem ainda ao papel paterno uma função ampla de provedor.

Conhecer as percepções e expectativas dos filhos sobre o cuidado parental é importante para o pai, para a mãe e para o contexto familiar, para que eles saibam mais a respeito dos papéis que Ihes são atribuídos, tanto 
ao nível real quanto ideal. Essas percepções, caracterizadas e atualizadas no meio familiar, podem ter repercussão também em outros ambientes nos quais a criança interage, como a escola. Nesse sentido, buscou-se compreender a partir da abordagem ecossistêmica proposta por Bronfenbrenner (2002) como a criança (que representa um subsistema) percebe os papéis parentais de cuidado e de interação dentro do microssistema familiar, tentando relacionar tais percepções também a mudanças sociais, culturais e econômicas da contemporaneidade (exossistema, macrossistema e cronossistema).

Desta forma, por meio de um estudo exploratório sobre as percepções das crianças, buscou-se identificar o que elas pensam sobre o papel paterno de cuidado, comparando-o com o papel materno de cuidado, a partir da seguinte questão: As percepções que os filhos têm a respeito do cuidado paterno, em termos reais e ideais, são diferentes das suas percepções em relação ao cuidado materno?

\section{Método}

\section{Participantes}

Participaram deste estudo 216 alunos, com faixa etária variando entre 10 e 11 anos, matriculados regularmente nas $4^{a}$ e $5^{2}$ séries do ensino fundamental de duas escolas públicas municipais da cidade de Florianópolis. Somente foram considerados os questionários das crianças cujos pais ou responsáveis assinaram o Termo de Consentimento Livre e Esclarecido. O projeto foi aprovado previamente pela Secretaria Municipal de Educação e pelo Comitê de Ética para Pesquisa em Humanos da Universidade Federal de Santa Catarina (protocolo 265/04).

\section{Instrumentos}

O questionário original é um instrumento elaborado por Bornstein et al. (1996) para mensurar como a mãe compreende maternagem real e ideal e paternagem real e ideal. Este foi adaptado para o Brasil por Maria Lucia Seidl de Moura e Rodolfo de Castro Ribas Jr., da Universidade do Rio de Janeiro (material não-publicado).
Para este estudo, o questionário foi reduzido e teve a linguagem adaptada para crianças, a partir da análise de dez pré-testes (Romanelli \& Biasoli-Alves, 1998), com o intuito de avaliar a percepção delas sobre o estilo parental de cuidado em aspectos reais e ideais. Além disso, para a verificação da consistência interna dos instrumentos, utilizou-se o teste Coeficiente Alfa de Cronbach (Bisquerra, Sarriera \& Martinez, 2004).

O questionário contém perguntas fechadas tipo escala ordinal e perguntas abertas complementares (Danna \& Matos, 1996; Ghiglione \& Matalon, 1993). O instrumento também é subdividido em duas escalas, que foram renomeadas para "escala de paternidade"e "escala de maternidade". A escala de paternidade contém duas subescalas, que são pai real e pai ideal, e a escala de maternidade outras duas subescalas, que são mãe real e mãe ideal. Pelo rearranjo entre elas constituem-se novas escalas, tais como pai real e mãe real (escala real) e pai ideal e mãe ideal (escala ideal).

Além disso, as questões da escala contemplam quatro categorias de investigação, reformuladas a partir do instrumento original para este estudo: a) cuidados diretos (questões um e dois), referente ao cuidado e à atenção parental dispensada à criança, que envolve necessidades básicas tais como higiene, alimentação, aquisição de material escolar, auxílio à criança em tarefas e aprendizagens e ajuda quando ela precisa de remédios ou está doente, como nos exemplos:"Eu acho que meu pai (minha mãe) cuida de mim naquilo que eu preciso (alimentação, roupas, materiais e deveres da escola, remédios etc.)?"e"O que ele(a) faz para cuidar de mim?"; b) cuidados indiretos (questão três), por meio da qual se investiga a percepção da criança a respeito de o pai (ou a mãe) propiciar um ambiente adequado, com objetos e situações, para uma melhor adequação e desenvolvimento da criança, como no exemplo: "Eu saio para passear e me divertir com meu pai (minha mãe)?" "Onde nós vamos?" e"O que eu faço com ele(a) para me divertir?"; c) interação social instrutiva (questões quatro e cinco), que diz respeito aos comportamentos parentais de instruir e apontar a disciplina, orientar para a importância de seguir regras e repreender o comportamento infantil, como no exemplo: "Meu pai (minha mãe) diz como eu devo ser para ter bom comportamento (ensina as regras, diz o que é certo e o que é errado)?" "O que ele(a) fala sobre ter bom comportamento?" Se eu me 
comporto mal, meu pai (minha mãe) fica triste?" e "O que acontece se eu não obedecer?"; d) interação social calorosa (questões seis e sete), para investigar os comportamentos parentais de se aproximar da criança por meio da brincadeira ou de manifestações positivas de afeto e carinho, como no exemplo: "Meu pai (minha mãe) brinca comigo (ou joga)?" "De que nós brincamos?" e "Meu pai (minha mãe) me dá carinho?" "Que tipo de carinho?" Essas questões que constituem a escala real foram reformuladas na forma escrita condicional para compor a ideal.

As opções de respostas às questões fechadas referentes à paternidade e à maternidade foram também adaptadas para facilitar a compreensão por parte das crianças. Para isso, a escala do tipo Likert foi transformada em escala ordinal, na qual se reduziu o número de opções de cinco para três ("sempre","às vezes"e"nunca"), para facilitar a compreensão semântica das respostas, e os itens "frequentemente" e "ocasionalmente" foram suprimidos (Pereira, 1999). Na escala ordinal, os valores atribuídos às respostas variam entre um e três, distribuídos sempre em ordem decrescente: 3 = sempre, $2=$ às vezes e $1=$ nunca.

\section{Procedimentos}

O primeiro procedimento foi a realização de um estudo piloto para melhor adequação do instrumento (linguagem) e verificação inicial de diferenças (teste $t$ de Wilcoxon); posteriormente o estudo foi realizado em duas escolas da rede municipal de ensino da cidade de Florianópolis. Cada criança respondeu a 28 questões, ao todo, obtendo-se uma média de oito sujeitos respondentes para cada item das escalas contidas nos questionários. A aplicação dos questionários foi realizada em grupos de seis crianças cada, em duas etapas distintas. No primeiro encontro com a pesquisadora, a criança respondeu ao questionário contendo a escala de paternidade; no segundo, ao questionário contendo a escala de maternidade.

Quanto a análise de dados, inicialmente foi realizada uma análise descritiva dos dados para caracterização da amostra. A prova $T$ das categorias com sinal de Wilcoxon foi utilizada para avaliar os dados do estudo piloto e do final, pelo cruzamento de todas as subescalas e verificação de diferenças entre as médias das categorias obtidas (Barbetta, 2002; Bisquerra et al., 2004).
Para a verificação da consistência interna dos resultados da escala, utilizou-se o teste Coeficiente Alfa de Cronbach (Bisquerra et al., 2004). Tanto no piloto quanto no estudo propriamente dito, verificaram-se amostras com características semelhantes, e houve consistência interna nos resultados das escalas; a média de todas as escalas foi de $\alpha=0,8170(\alpha \geq 0,75)$. Esses dados são indicativos de estabilidade interna entre os resultados, do que se pode concluir que todas as escalas são instrumentos confiáveis para mensurar possíveis diferenças entre a percepção dos filhos sobre o cuidado parental. Na análise do material escrito, obtido pelas questões abertas, utilizou-se a Análise de Conteúdo Temática (Bardin, 1979).

\section{Resultados}

\section{Caracterização da amostra}

Dentre os participantes do estudo, $57 \%$ eram do sexo feminino e $52 \%$ tinham dez anos. No que diz respeito a residir com familiares, $62 \%$ das crianças moravam com ambos os pais, $30 \%$ moravam somente com a mãe, 3\% com os avós e 5\% somente com o pai.

Para o tratamento dos resultados obtidos na escala de paternidade, comparando as médias das subescalas pai real e pai ideal do estudo final, utilizou-se prova $T$ das Categorias com Sinal de Wilcoxon ( $T$ ) (Tabela 1).

Na prova $T$ das Categorias com Sinal de Wilcoxon, obteve-se diferença estatisticamente significativa em seis dos sete pares de médias que comparavam pai real e pai ideal. Os resultados são indicativos de que há

Tabela 1. Valores da prova $T$ atribuídos pelas crianças $(n=216)$ na escala de paternidade.

\begin{tabular}{lccc}
\hline & Pai real x Pai ideal & \multicolumn{2}{c}{ Soma da prova de sinais $(T)$} \\
\cline { 2 - 3 } Questões & Negativas & Positivas & \\
\hline 1 & 144,00 & 1081,00 & $0,000^{*}$ \\
2 & 205,00 & 1335,00 & $0,000^{*}$ \\
3 & 51,00 & 1965,00 & $0,000^{*}$ \\
4 & 169,00 & 692,00 & $0,000^{*}$ \\
5 & 495,00 & 681,00 & 0,311 \\
6 & 105,00 & 1221,00 & $0,000^{*}$ \\
7 & 115,00 & 626,00 & $0,000^{*}$ \\
\hline
\end{tabular}

${ }^{*} p \leq 0,01$ 
diferença significativa entre a percepção que as crianças têm do pai real em relação ao pai ideal. Para elas, o pai real precisa estar mais presente para se aproximar do ideal em aspectos como: cuidado, que implica higiene, alimentação, auxílio nas tarefas escolares, providência de materiais escolares e remédios (questão 1); atenção para o cuidado, percebendo essas mesmas necessidades de cuidado delas (questão 2); diversão e passeios (questão 3), orientação sobre regras de comportamento (questão 4); brincadeira ou jogo (questão 6) e manifestação de carinho (questão 7). As diferenças estão presentes em todas as categorias investigadas, o que sugere que o papel real do pai deve abranger mais cuidados diretos, indiretos e interações sociais instrutivas e calorosas, para que corresponda ao papel ideal que seus filhos the atribuem. Os resultados referentes à análise quantitativa da escala de maternidade, analisados por meio da Prova de Wilcoxon (T) e das subescalas mãe real e mãe ideal (Tabela 2).

Os resultados da prova $T$ para a escala de maternidade são indicativos de que a mãe real se aproxima da mãe ideal na percepção dos filhos, por não terem sido encontradas diferenças estatisticamente significativas em quatro dos sete pares de médias analisados, que abrangem aspectos como: propiciar cuidado direto em relação às necessidades de higiene, alimentação, escolares e medicação (questão 1) e ter atenção para saber identificar as necessidades de cuidado (questão 2), e na interação social instrutiva de orientar melhor o comportamento (questão 4). Quanto a repreender de forma indireta o mau comportamento (questão 5), as crianças atribuíram escores maiores à mãe real em relação à ideal.

Entretanto, na prova $T$ há diferenças estatisticamente significativas nos pares de questões três e seis, que se referem respectivamente ao fato de a criança sair para passear ou se divertir com a mãe e brincar com ela (cuidados indiretos e interação social calorosa). No par de questões de número sete, há diferença significativa no que diz respeito à expectativa da criança em relação à manifestação de carinho da mãe (interação social calorosa). A partir desses resultados, pode-se afirmar que, na escala de maternidade, as expectativas das crianças em relação ao cuidado materno real aproximam-se do ideal, principalmente em aspectos que envolvem cuidados diretos e interação social instrutiva (Tabela 3).
Tabela 2. Valores da prova Tatribuídos pelas crianças $(n=216)$ na escala de maternidade.

\begin{tabular}{|c|c|c|c|}
\hline \multirow[b]{2}{*}{ Questões } & \multicolumn{2}{|c|}{ Soma da prova de sinais $(T)$} & \multirow{2}{*}{$p$} \\
\hline & Negativas & Positivas & \\
\hline 1 & 70,00 & 120,00 & 0,251 \\
\hline 2 & 52,50 & 67,50 & 0,637 \\
\hline 3 & 157,50 & 832,50 & $0,000^{* *}$ \\
\hline 4 & 64,00 & 56,00 & 0,796 \\
\hline 5 & 498,00 & 282,00 & 0,100 \\
\hline 6 & 120,00 & 1155,00 & $0,000^{* *}$ \\
\hline 7 & 66,00 & 165,00 & $0,050^{*}$ \\
\hline
\end{tabular}

${ }^{*} p \leq 0,05 ;{ }^{* *} p \leq 0,01$.

Tabela 3. Valores da prova Tatribuídos pelas crianças $(n=216)$ na escala real.

\begin{tabular}{lccc}
\hline & Pai real xMãe ideal & \multicolumn{2}{c}{ Soma da prova de sinais $(T)$} \\
\cline { 2 - 3 } Questões & Negativas & Positivas & \\
\hline 1 & 177,00 & 1148,00 & $0,000^{*}$ \\
2 & 74,00 & 1304,00 & $0,000^{*}$ \\
3 & 312,00 & 1399,00 & $0,000^{*}$ \\
4 & 85,00 & 618,00 & $0,000^{*}$ \\
5 & 228,50 & 899,50 & $0,000^{*}$ \\
6 & 844,00 & 986,00 & 0,571 \\
7 & 153,00 & 837,00 & $0,000^{*}$ \\
\hline
\end{tabular}

${ }^{*} p \leq 0,01$.

Pelos resultados da prova $T$ de Wilcoxon, seis dos sete pares de questões apresentaram diferenças estatisticamente significativas. Esses resultados são indicativos de que o pai real é percebido de maneira diferente da mãe real, estando ela bem mais presente nos cuidados diretos, indiretos e na interação social instrutiva e calorosa em aspectos como: propiciar cuidado direto em relação às necessidades de higiene, de alimentação, escolares e de saúde (questão 1); ter atenção para saber identificar as necessidades de cuidado (questão 2); sair para passear ou se divertir (questão 3); orientar o comportamento (questão 4); repreender de forma indireta o mau comportamento (questão 5); manifestar carinho (questão 7). Apenas no par número seis, que se refere ao fato de os pais brincarem com os filhos, não houve diferença estatisticamente significativa. Os resultados da prova $T$ calculados nas subescalas pai ideal e mãe ideal são descritos na Tabela 4, constituindo a escala ideal.

Na prova $T$ de Wilcoxon, apenas um dos sete pares de questões apresentou diferença estatisticamen- 
Tabela 4. Valores da prova T atribuídos pelas crianças $(n=216)$ na escala ideal.

\begin{tabular}{lccc}
\hline & Pai real xMãe ideal & \multicolumn{3}{c}{ Soma da prova de sinais $(T)$} & \\
\cline { 2 - 3 } Questões & Negativas & Positivas & \\
\hline 1 & 54,00 & 99,00 & 0,225 \\
2 & 47,50 & 162,50 & $0,019^{*}$ \\
3 & 225,00 & 210,00 & 0,853 \\
4 & 87,50 & 143,50 & 0,292 \\
5 & 219,00 & 376,00 & 0,161 \\
6 & 441,50 & 299,50 & 0,266 \\
7 & 176,00 & 352,00 & 0,063 \\
\hline
\end{tabular}

${ }^{*} p \leq 0,05$.

te significativa. Esses resultados são indicativos de que somente no que se refere a ter atenção para saber identificar as necessidades de cuidado as crianças idealizam mais cuidados da parte materna. No geral, as crianças têm expectativas ideais altas em relação ao cuidado eà interação com ambos os pais.

\section{Análise de conteúdo}

Para aprofundar a caracterização paterna e materna de cuidado e de interação na percepção dos filhos, foi realizada a análise de conteúdo. Nesta análise, todo o material escrito obtido das questões abertas dos 216 questionários foi codificado em 3820 unidades de contexto (frases), contendo 456 unidades de registro (determinadas por classes de palavras: verbos, substantivos, adjetivos e advérbios) que, agrupadas, deram origem a 188 unidades temáticas. A média de respostas codificadas por participante ficou em 34,2. A frequência, em porcentagem ( $p$ ), foi obtida a partir da incidência da unidade temática sobre o número total de respostas dadas a cada questão. Nos resultados, para cada questão foram descritas somente as unidades temáticas mais frequentes. Todas as respostas que continham erros foram corrigidas na forma escrita para facilitar a compreensão do leitor. Cita-se uma frase original para exemplificar: "As coisas que não sei para mim ser bem comportado".

Por meio das respostas dadas à categoria cuidados diretos, pode-se observar que o papel principal que as crianças percebem como associado ao cuidado paterno real é o de provedor (70\%). São exemplos:"Ele compra roupas para mim" (sujeito EF 28) e "Ele dá pensão para comprar comida" (sujeito EF 105). Em termos ideais, as crianças esperam uma diminuição do papel de provedor (50\%) e um aumento do cuidado direto (19\%), principalmente no que se refere ao pai estar mais em casa e atento ao cuidado da criança.

Na mesma questão referente à mãe, pode-se observar que o papel principal que as crianças percebem como associado ao cuidado materno real é o de prover recursos materiais (47\%): "Compra roupas e calçados" (sujeito EF 77). Em termos ideais, 19\% das crianças esperam receber mais atenção da mãe (pelas conversas): "Devia conversar mais comigo" (sujeito EF 22), e apenas 17\% atribuem à mesma o papel de provedora. Entretanto, a maior parte das crianças percebe que a mãe ideal já faz tudo o que é possível para o cuidado delas (21\%).

Com relação aos cuidados indiretos, que se referem a sair para passear e divertir-se com o pai, em termos ideais, os filhos esperam mais (54\%) do que o cuidado real que o pai oferece (48\%), como nos exemplos"Brincar no parque de diversões" (sujeito EF 27) e "Jogar bola e videogame" (sujeito EF 31). Contudo, em termos reais, chama atenção o tipo de passeio realizado pela maioria das crianças em companhia dos pais. A grande maioria das crianças afirma que passeia em centros de compras, cuja única diversão relatada é comprar objetos, brinquedos e roupas: "Vamos ao shopping comprar" (sujeito EF 35).

Nessa mesma categoria, a maioria das crianças (83\%) afirma que as mães as levam para passear em diversos lugares (centros de compras, passeios culturais e recreativos, visitas a parentes e amigos). Entretanto, assim como nas respostas atribuídas ao pai nesta questão, os passeios mais frequentes acontecem em centros comerciais, e a principal atividade realizada junto à mãe é comprar.

$\mathrm{Na}$ categoria que investigou a interação social instrutiva, observou-se que, em termos reais, para quase metade das respostas (43\%) as crianças percebem que o pai dá uma orientação geral sobre ter bom comportamento. Isso é visível nos exemplos "Que eu devo ter educação" (sujeito EF 29) e "Que eu devo ter boas maneiras" (sujeito EF 38), mas para a maioria delas o ideal seria que o pai orientasse de forma mais específica o comportamento (72\%):"As coisas que eu não sei para ser bem comportado" (Sujeito EF 67) e "Como eu devo ser para ser bem educado" (sujeito EF 25). Essas respostas 
evidenciam que a criança possivelmente não teve parâmetros para saber exatamente o que esperam dela a respeito de seu comportamento frente aos diversos ambientes e situações.

Em termos reais, para mais da metade das respostas (55\%) as crianças percebem que a mãe dá uma orientação geral sobre ter bom comportamento. Da mesma forma que em relação ao pai, para a maioria delas o ideal seria que a mãe orientasse de forma mais específica o comportamento (68\%).

Quanto às medidas de contenção do pai sobre comportamentos indesejáveis de seus filhos, em termos reais, quase um terço das crianças afirma receber castigo (27\%), e um número um pouco maior considera ideal receber castigo (31\%). Contudo, as crianças deste estudo referem-se, em sua maioria, a castigos relacionados à proibição de atividades prazerosas, tais como "Não posso jogar videogame" (sujeito EF 12) e"Deixar-me de castigo sem ver televisão" (sujeito EF 89).

Quanto às medidas de contenção da mãe sobre comportamentos indesejáveis de seus filhos, em termos reais, quase um terço das crianças afirma receber castigo (30\%), e um número um pouco maior considera ideal receber castigo (32\%). Assim como nas respostas atribuídas ao pai, os castigos a que estas crianças se referem são somente restritivos das atividades prazerosas.

Pelos temas mais representativos da categoria interação social calorosa (que se refere à brincadeira eà demonstração de carinho), muitas crianças citam jogos diversos que praticam com o pai (77\%), mas em termos ideais, todas elas esperam brincar mais e sugerem tipos mais diversificados de atividades (100\%). Cabe mencionar que um considerável número de crianças afirma nunca brincar com o pai (23\%). No que diz respeito à demonstração de carinho pelo pai, a maioria das crianças espera um pouco mais do pai real (81\%) em relação ao ideal (90\%). Algumas delas afirmam que o pai nunca demonstra carinho (10\%).

Quanto a esse mesmo tipo de interação com a mãe, muitas crianças citam jogos e brinquedos diversos que praticam com a mãe (73\%), mas em termos ideais, todas elas esperam brincar mais e sugerem tipos mais diversificados de atividades (94\%). Cabe mencionar que um considerável número de crianças afirma nunca brincar com a mãe (25\%), e somente algumas pensam que a mãe ideal não precisa brincar (6\%). Quanto ao carinho que recebem da mãe, essas crianças parecem estar mais satisfeitas, tanto em termos reais (90\%) quanto ideais (92\%). Poucas delas afirmam que a mãe dá carinho de outras formas, por exemplo, verbalizando ou pela brincadeira.

\section{Discussão}

No sentido de compreender o papel do pai no contexto familiar, bem como as relações e as interações que ocorrem entre a tríade pai/mãe/criança, procurou-se caracterizar a percepção dos filhos sobre as práticas de cuidado parental porque não se teve acesso a muitos estudos semelhantes no que diz respeito à ênfase na opinião dos filhos como integrantes do microssistema familiar. Pretendeu-se, portanto, acrescentar dados novos à compreensão do sistema familiar.

Considerando que este estudo teve uma amostra com características semelhantes às da população em geral no que diz respeito ao estado civil dos pais, pois aproximadamente $70 \%$ das crianças moram com ambos os pais e 30\% delas somente com a mãe (IBGE, 2000), pode-se afirmar que mãe e pai desempenham papéis diferentes no cuidado direto e indireto de suas crianças neste estudo. Da mesma forma, pai e mãe representam para os filhos modelos distintos de interação social, tanto instrutiva quanto calorosa (Bandeira et al., 2005). Tais diferenças são percebidas pelas respostas das crianças, que afirmam que o pai real está mais distanciado do ideal no que se refere a cuidado, atenção, diversão, orientação, brincadeira e carinho. A mãe real, ao contrário, está mais próxima da expectativa ideal dessas crianças. Ainda assim, em aspectos como diversão, brincadeira e carinho, os filhos esperam mais. Tais resultados são semelhantes aos encontrados em estudos anteriores, que evidenciam diferenças no desempenho dos papéis parentais, estando a mãe mais envolvida no cuidado e o pai no sustento econômico da família (Araújo, 2002; Kreppner, 2000).

Quando os resultados atribuídos aos pais são comparados em termos reais, eles são bastante diferentes no que diz respeito aos cuidados e à interação, estando a mãe predominantemente mais presente. Contudo, quando se faz a comparação em termos ideais, as crianças atribuem semelhanças nesses aspectos de cuidado e interação parentais, com expectativas altas 
em relação a ambos. Esses resultados são indicativos de que, na expectativa ideal dos filhos, ambos os pais deveriam compartilhar as tarefas parentais, estando mais presentes no cuidado e na interação.

A partir dos dados obtidos na categoria interação social instrutiva, observou-se que em termos reais a mãe orienta mais as crianças. Mas o ideal, para elas, é que o pai também oriente mais. Além disso, a maioria das crianças considera ideal receber orientações mais específicas sobre as regras de comportamento. Parece que elas, por vezes, não sabem o que o pai e a mãe esperam a respeito de seu comportamento, e quando se considera a complexidade e a diversidade de ambientes e situações nas quais a criança precisa desempenhar papéis também distintos e complexos, pode-se compreender que ambos os pais poderiam fornecer uma orientação mais precisa e minuciosa às suas crianças. Esses resultados sobre as expectativas das crianças são concordantes com os encontrados em estudos anteriores, segundo os quais o pai atual tem uma característica de educador na vida das crianças (Araújo, 2002; Aspesi et al., 2005; Coelho, 2000; Dessen \& Braz, 2000; Lewis, 2000; Wagner et al., 2005).

Quanto às medidas de contenção do pai e da mãe sobre comportamentos indesejáveis da criança, chama atenção neste estudo o fato de que as crianças idealizam receber mais castigos do que recebem. No entanto, parece que isso se deve ao fato de elas preferirem castigos (somente associados à privação de atividades prazerosas) em vez de repreensões verbais severas, nas quais, segundo elas, ambos os pais costumam gritar e xingar muito. A esse respeito, é importante ressaltar que elas sabem da necessidade de punição e consideram-na adequada quando se comportam de maneira indesejável ou inadequada.

Cabe considerar, também, que o desempenho de papéis parentais no meio familiar pode ter fortes determinantes sociais, econômicos, históricos e culturais. Nesse sentido, a ideologia capitalista dominante na sociedade pode estar associada a muitas mudanças, que determinam a configuração e o funcionamento da família contemporânea. Uma das principais mudanças está relacionada ao papel feminino (Araújo, 2002; Dessen \& Braz, 2000; Fleck \& Wagner, 2003; Polônia et al., 2005).

As mulheres passaram a se inserir maciçamente no mercado de trabalho, voltando a estudar e buscando melhores oportunidades e colocação profissional. A partir daí, elas assumiram largamente também o papel de coprovedoras, quando não são as únicas provedoras do lar. Por meio deste estudo, constata-se que as crianças atribuem um amplo papel de provedor a ambos os pais. A mãe, tanto quanto o pai, busca atender às necessidades materiais dos filhos, e ambos parecem movidos a suprir também as "demandas consumistas" das crianças.

A esse respeito, constata-se pelos resultados obtidos na categoria cuidados indiretos que os passeios mais frequentes que as crianças realizam com o pai e a mãe ocorrem em centros de compras, nos quais a única diversão é a atividade de comprar. Não se deve desconsiderar o fato de que muitas famílias levam as crianças às compras simplesmente para que elas não fiquem sozinhas em casa. Contudo, é importante ressaltar que o ideal para elas seria realizar passeios recreativos e culturais com ambos os pais, nos quais pudessem se divertir e brincar. Nesse sentido, observa-se a imposição de um macrossistema capitalista sobre o microssistema familiar, determinando mudanças expressivas no cuidado parental que os pais dispensam aos filhos, assim como na interação que mantêm com eles. A partir deste ideal dos filhos, sugere-se que, apesar da invasão consumista a que estão constantemente submetidas as crianças do mundo contemporâneo, elas ainda conservam um desejo característico do mundo infantil: brincar, criar um mundo de fantasia, ouvir histórias, sorrir e se divertir.

Nesse contexto ecológico familiar, a mulher que sai para trabalhar e representa força nesse sentido continua desempenhando com versatilidade os múltiplos papéis que lhe são atribuídos como mãe, esposa, dona de casa e profissional, parecendo suprir as demandas real e ideal de forma predominantemente satisfatória na opinião dos filhos. O homem, por sua vez, começa a desempenhar novos e diferentes papéis junto à família, mas os filhos esperam ainda mais para que o pai se aproxime do ideal deles. Esses movimentos e alterações de cada membro podem ser compreendidos como uma busca constante de equilíbrio, característica do subsistema familiar, cujos fins últimos são a adaptação e o desenvolvimento do todo. Cabe ressaltar que os resultados deste estudo são limitados, à medida que os dados obtidos são referentes ao conhecimento de um contexto histórico e ecológico específico e sem o devido controle de variáveis como a situação socioeconômica e educacional dos pais das crianças. 


\section{Referências}

Araújo, V. R. O. A. (2002). Reflexões sobre a família e educação na modernidade. Estilos da Clínica, 7 (12), 100-111.

Aspesi, C. C., Dessen, M. A., \& Chagas, J. F. (2005). A ciência do desenvolvimento humano: uma perspectiva interdisciplinar. In M. A. Dessen \& A. L. Costa Jr (Orgs.), A ciência do desenvolvimento humano: tendências atuais e perspectivas futuras (pp.19-36). Porto Alegre: Artmed.

Bandeira, M., Goetz, E. R., Vieira, M. L., \& Pontes, F. A. R. (2005). O cuidado parental e o papel do pai no contexto familiar. In F. A. R. Pontes, C. M. C. Magalhães, R. C. S. Brito \& W. L. B. Martin (Orgs.), Temas pertinentes à construção da psicologia contemporânea (pp.191-230). Belém: EDUFPA.

Barbetta, P. A. (2002). Estatística aplicada às ciências sociais. Florianópolis: UFSC.

Bardin, L. (1979). Análise de conteúdo. Lisboa: Edições 70.

Berger, P. L., \& Luckmann, T. (2000). A construção social da realidade: tratado de sociologia do conhecimento. Petrópolis: Vozes.

Bisquerra, R., Sarriera, J. C., \& Martinez, F. (2004). Introdução à estatística: enfoque informático com o pacote estatístico SPSS. Porto Alegre: Artmed.

Bornstein, M. H., Tamis-LeMonda, C. S., Parcual, L., Haynes, O. M., Painter, K. M., Galperín, C. Z., \& Pêcheux, M. G. (1996). Ideas about parenting in Argentina, France and the United States. International Journal of Behavioral Development, 19 (2), 347-367.

Bronfenbrenner, U. (1986). Ecology of the family as a context for human development: research perspectives. Developmental Psychology, 22 (6), 723-742.

Bronfenbrenner, U. (1994). Ecological models of human development. In T. Husen \& T. N. Postelethwaite (Orgs.), Encyclopedia of education (2nd ed., pp.1643-1647). Oxford: Elsevier.

Bronfenbrenner, U. (2002). A ecologia do desenvolvimento humano: experimentos naturais e planejados (2a ed.). Porto Alegre: Artes Médicas.

Bronfenbrenner, U., \&Evans, G. (2000). Development science in the 21st century: emerging questions, theoretical models, research designs and empirical findings. Social Development, 9 (1), 115-125.

Coelho, S.V. (2000). As transformações da família no contexto brasileiro: uma perspectiva das relações de gênero. Psique, 12 (4), 658-664.

Danna, M. F., \& Matos, M. A. (1996). Ensinando observação: uma introdução. São Paulo: Edicon.

Dessen, M. A., \& Braz, M. P. (2000). Rede social de apoio durante transições familiares decorrentes do nascimento de filhos. Psicologia: Teoria e Pesquisa, 16 (3), 221-231.

Fleck, A. C., \& Wagner, A. (2003). A mulher como principal provedora do sustento econômico familiar. Psicologia em Estudo, 8 (número especial), 31-38.
Geary, D. C., \& Flinn, M. V. (2001). Evolution of human parental behavior and human family. Parenting: Sience and Practice, 1 (1-2), 5-61.

Ghiglione, R., \& Matalon, B. (1993). Oinquérito:teoria e prática. Oeiras: Celta Editora.

Instituto Brasileiro de Geografia e Estatística. Censo (2000). Recuperado em maio 15, 2005, disponível em www. ibge.gov.br/censo

Klaus, M. H., Kennell, J. H., \& Klaus, P. H. (2000). Vínculo: construindo as bases para um apego seguro e para a independência. Porto Alegre: Artes Médicas.

Kreppner, K. (2000). The child and the family: interdependence in developmental pathways. Psicologia: Teoria e Pesquisa, 1 (16), 111-22.

Lewis, C. (2000). A man's place in the home:fathers and families in the UK. York: Joseph Rowntree Foundation.

Lewis, C., \& Dessen, M. A. (1999). O pai no contexto familiar. Psicologia: Teoria e Pesquisa, 15 (1), 9-16.

Maridaki-Kassotaki, K. (2000). Undertanding fatherhood in Greece: father's involvement in child care. Psicologia: Teoria e Pesquisa, 16 (3), 213-219.

Pereira, J. C. R. (1999). Análise de dados qualitativos: estratégias metodológicas para as ciências da saúde, humanas esociais. São Paulo: Edusp.

Polonia, A C., Dessen, M. A., \& Silva, N. L. P. (2005). O modelo bioecológico de Bronfenbrenner: Contribuições para o desenvolvimento humano. In M. A. Dessen \& A. L. Costa Jr (Orgs.), A ciência do desenvolvimento humano: tendências atuais e perspectivas futuras (pp.190-209). Porto Alegre: Artmed.

Prado, A. B. (2005). Semelhanças e diferenças entre homens e mulheres na compreensão do comportamento paterno. Dissertação de mestrado não-publicada, Universidade Federal de Santa Catarina, Florianópolis.

Romanelli, G., \& Biasoli-Alves, Z. M. M. (1998). Diálogos metodológicos sobre prática de pesquisa. Ribeirão Preto: Legis Summa.

Seidl de Moura, M. L., \& Ribas Jr., R. C. (2003). Algumas informações sobre o instrumento estilo materno e paterno. Relatório parcial do projeto: interação mãe-bebêe desenvolvimento infantil: um estudo longitudinal e transcultural. Material não-publicado, Universidade do Estado do Rio de Janeiro.

Veneziano, R. A. (2003). The importance of paternal warmth. Cross-Cultural Research, 37 (3), 265-281.

Wagner, A., Predebon, J., Mosmann, C., \& Verza, F. (2005). Compartilhar tarefas? Papéis e funções de pai e mãe na família contemorânea. Psicologia:Teoria e Pesquisa, 21 (2), 181-186.

Recebido em: 8/3/2007

Versão final reapresentada em: 29/8/2007

Aprovado em: 11/3/2008 
